\title{
Ultrastructure of the scolex, rhyncheal system and bothridial pits of Otobothrium mugilis (Cestoda: Trypanorhyncha)
}

\author{
Malcolm K. Jones
}

Centre for Microscopy and Microanalysis, The University of Queensland, St Lucia, Queensland 4072, Australia

Key words: Cestoda, Trypanorhyncha, Otobothrium, scolex, rhyncheal system, ultrastructure, phylogeny

\begin{abstract}
The ultrastructure of the scolex tegument, bothridial pits (=ciliated pits) and rhyncheal system of Otobothrium mugilis Hiscock, 1954 is described from plerocerci collected from the teleosts Arius graeffei Kner et Steindachner and Mugil cephalus Linnaeus. Scanning electron microscopy revealed that filamentous microtriches with shortened caps are abundant across the entire surface of the tegument. Palmate microtriches are dominant on the bothridia and their margins. The surfaces of bothridial pits were covered with large bifid microtriches. The bothridial pits are strongly muscularised invaginations of the tegument. Nervous tissues were not observed within the pits and it is probable that these structures function as accessory attachment structures. The wall of each tentacle sheath consists of one to three bands of fibrils, lined internally by a thin cytoplasmic layer. The tentacular walls are cellular, containing myofilaments. The fibrils of the tentacular walls are arranged into discrete blocks of parallel fibrils and appear to be intracellular. Tentacular walls are lined externally by a modified membrane with an external glycocalyx. Tentacular hooks are solid, bound externally by a membrane. The body of the hook contains numerous longitudinal canaliculi and an electron-opaque medulla lies at the centre of the hook.
\end{abstract}

The order Trypanorhyncha (Platyhelminthes: Cestoidea) contains species that inhabit the spiral intestines and pyloric stomachs of elasmobranch fishes as adults. Trypanorhynchs possess an unique holdfast consisting of two or four bothridia and four retractile, armed tentacles (Campbell and Beveridge 1994). The tentacles are withdrawn and everted from tentacular sheaths by other components of the rhyncheal system, namely, the muscular bulbs and retractor muscles (Wardle and McLeod 1952).

In recent years, two taxonomic systems have been proposed for the Trypanorhyncha. The system of Campbell and Beveridge (1994) follows that of Dollfus (1942) and classifies the trypanorhynchs largely on the arrangement of tentacular hooks as well as the structure of the scolex, mature proglottides and metacestodes. Campbell and Beveridge (1994) recognised four superfamilies, the Homeoacanthoidea, Heteroacanthoidea, Otobothrioidea and Poecilacanthoidea. This system is supported in part by a recent cladistic analysis of trypanorhynch cestodes (Beveridge et al. 1999).

The system of Palm (1997) uses easily recognisable characters, namely number of bothridia, and the presence or absence of bothridial (=ciliated) pits and prebulbar organs to distinguish major taxa of the Trypanorhyncha, with tentacular armature receiving less attention. Palm (1997) proposed three superfamilies, the Tentacularioidea, Otobothrioidea, and Eutetrarhynchoidea based solely on the presence or absence of the two latter characters. The strength of Palm's system lies in its simplicity as families in each superfamily are distinguished by easily recognised characters. The weakness of the system is the lack of support from a recent cladistic analysis (Beveridge et al. 1999). This analysis of morphological character states in the Trypanorhyncha has suggested, for example, that bothridial pits, a key feature in Palm's (1997) classification, have arisen on several occasions in the order and may be of limited systematic value.

The two systematic accounts of the Trypanorhyncha use morphological features of the scolex, namely, bothridial pits and tentacular hooks, as primary characters for distinguishing taxa. Very little is known about the functional morphology of these structures, particularly the bothridial pits (Palm 1997). In this paper, the ultrastructure of the scolex and rhyncheal system of Otobothrium mugilis Hiscock, 1954 is described to provide comparative morphological and functional information on these scolex structures for use in systematic and phylogenetic investigations of the Trypanorhyncha. Knowledge of the ultrastructural features of Otobothrium species has come from scanning electron microscopy studies of the scolex (Shields 1985, Palm et al. 1993, Palm 1995) and a single investigation of the tegument of $O$. insigne by Hildreth and Lumsden (1987), but none of these papers have detailed the internal structure of the bothridial pits or the rhyncheal system.

Throughout this paper, the term bothridial pit is used to define specialised pits that occur along the posterolateral margin of some trypanorhynchs. Earlier authors favoured such terms as ciliated pit, sensory fossette, or retractile organ for these structures (Pintner 1934, Wardle and McLeod, 1952). This paper will show that 
pits do not contain cilia or sensory structures and hence, the new term is proposed as a term of convenience that is consistent with modern cell biology and defines the nature and location of the pits.

\section{MATERIALS AND METHODS}

Plerocerci of Otobothrium mugilis were obtained from the mesenteries of catfish Arius graeffei Kner and Steindachner from the Brisbane River, and Mugil cephalus Linnaeus from Heron Island, Queensland, Australia. Plerocerci were teased from their surrounding tissues and dissected from cysts prior to fixation.

For scanning electron microscopy (SEM), plerocerci were cleaned of mucus by vigorous shaking in saline; this method removed debris from the surface of the organism and, fortuitously, caused the tentacles to evert. Cleaned specimens were fixed in hot saline and transferred to $3 \%$ glutaraldehyde in $0.1 \mathrm{M}$ cacodylate buffer $\mathrm{pH} 7.2$ or $4 \%$ aqueous formaldehyde. After three buffer rinses, the specimens were post-fixed in $1 \%$ aqueous osmium tetroxide and dehydrated in a graded series of ethanols. The specimens were transferred from $100 \%$ ethanol to $100 \%$ hexamethyldisilazane (ProSciTech, Towns-ville, Australia) and allowed to dry overnight. Dried specimens were mounted onto stubs, coated with gold and viewed in a JSM 6300 field emission scanning electron microscope at accelerating voltages of $5-20 \mathrm{kV}$.

Specimens for transmission electron microscopy (TEM) were fixed in $3 \%$ glutaraldehyde in $0.1 \mathrm{M}$ cacodylate buffer ( $\mathrm{pH}$ 7.2). After rinses in cacodylate buffer, the specimens were post-fixed in $1 \%$ aqueous osmium tetroxide or potassium ferricyanide-reduced osmium tetroxide fixative, consisting of $1 \%(\mathrm{w} / \mathrm{v})$ osmium tetroxide and $1.5 \%(\mathrm{w} / \mathrm{v})$ potassium ferricyanide in distilled water. Specimens were dehydrated in ethanol, transferred to anhydrous acetone and embedded in Epon (ProSciTech, Townsville, Australia). Ultrathin sections were photographed using a JEM 1010 transmission electron microscope, operating at accelerating voltages of 60 or $80 \mathrm{kV}$.

\section{RESULTS}

\section{General features}

The general anatomy of the scolex of Otobothrium mugilis has been described by Hiscock (1954) and brief mention of the major features is made here. The scolex has two patelliform bothridia (Figs. 1, 6), each with a distinct margin (Fig. 2). A pair of bothridial pits is present on the postero-lateral margin of each bothridium (Figs. 1-3). Four tentacles emerge from the apex of the scolex (Fig. 1). Each tentacle is connected by a sinuous tentacular sheath to one of four muscular bulbs that lie in the pars bulbosa (Fig. 6). The scolex is craspedote and the pygidium is slightly longer than wide (Fig. 6).

\section{Tegument}

The scolex of $O$. mugilis is lined by a syncytial tegument (Figs. 7, 8, 11-13). The apical cytoplasm is of uniform thickness and consistency throughout the scolex, being rich in electron-opaque discoid bodies (Fig. 13). There is marked diversity of microtriches on the surface of the scolex. Filamentous microtriches, with drastically shortened caps (Figs. 8, 11, 13) cover all surfaces of the scolex and are the only microtriches on all surfaces except those of the bothridia. The microtriches covering the bothridia are predominantly palmate (Figs. 3, 4, 7, 13). These microtriches are approximately $1 \mu \mathrm{m}$ long having usually 5 prongs, although microtriches with 3 or 4 prongs are common (Fig. 4). Palmate microtriches do not occur on the posterior extremities of the bothridia (Fig. 2).

The microtriches of the bothridial pits (Figs. 5, 11, 12) are stout, with a cap that is approximately $5 \mu \mathrm{m}$ long (Figs. 11, 12). The caps are embedded deeply in the apical cytoplasm (Figs. 11, 12). These microtriches are bifid and pincer-like (Fig. 5) and the bifid process is approximately $0.5 \mu \mathrm{m}$ in length.

\section{Bothridial pits}

The bothridial pits of $O$. mugilis are tegument-lined invaginations of the bothridia (Figs. 11, 12). The apical cytoplasm lining the bothridial pits is of the same thickness as that of surrounding regions of the bothridia (Fig. 11). Tegumentary vesicles are less abundant in the bothridial pits than in surrounding regions (Fig. 12). The apical cytoplasm is underlain by many layers of smooth circular muscles and a single retractor muscle extends from the base of the pit into deeper regions of the bothridium (Fig. 11). Sensory receptors or other components of the nervous system were not observed in any section of the bothridial pits although ciliated sensory receptors are observed occasionally on the bothridial tegument adjacent to the pits (not figured).

\section{Rhyncheal system}

The rhyncheal system of Otobothrium extends longitudinally through the medullary regions of the pars vaginalis and pars bulbosa (Fig. 6). The system is embedded in the parenchyma of the pars vaginalis and pars bulbosa and is surrounded by a conical sleeve of glycogen-rich parenchymal cells (Figs. 6, 8). This cellrich sleeve is in turn surrounded by a predominantly acellular and fibrillar extracellular matrix (Figs. 6-8). Throughout much of the pars vaginalis, the apical cytoplasm of the tegument is attended by a thin and discontinuous subtegumentary musculature.

The tentacular bulbs consist of layers of striated muscles surrounding a bulb lumen (Fig. 10). The striated muscle is arranged into discrete blocks of myofibrils. A thin and discontinuous lining of cytoplasm containing mitochondria is found along the bulb lumen (Fig. 10). A retractor muscle is present within the sheath and bulb, and consists of discrete bundles of smooth muscles (not figured).

Tentacular sheaths extend from the bulbs to the apex of the scolex where they become the tentacular wall. A band of longitudinal muscles is present in the parenchyma along the inner margin of each sheath (Fig. 9). The sheath wall is composed of one to three bands of 

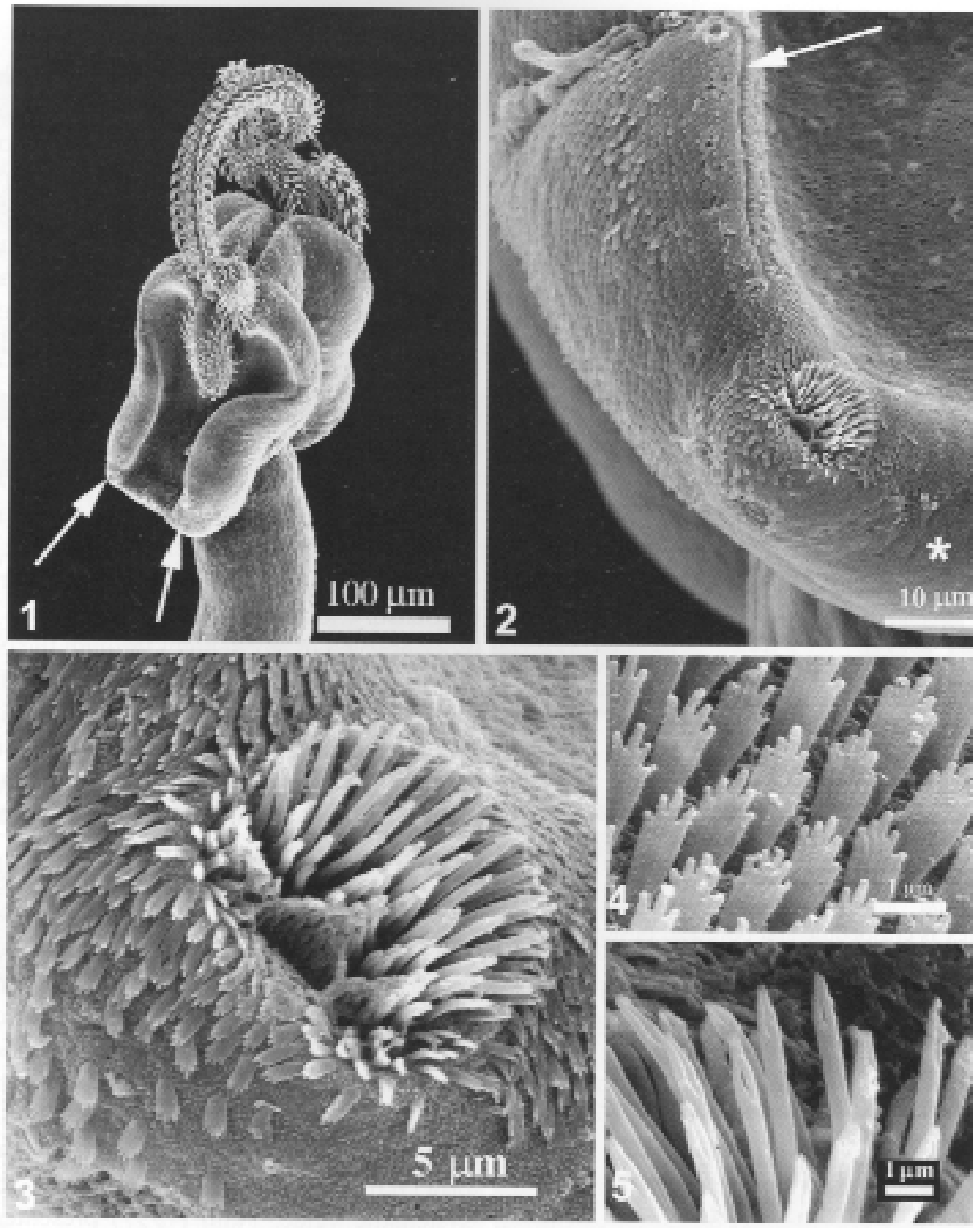

Figs. 1-5. Otobothrium mugilis, SEM. Fig. 1. Scolex. Bothridial pits are present along the postero-lateral margins of the bothridium (arrows). Fig. 2. Bothridial margin. A distinct furrow (arrow) is evident along the lateral margin of the bothridium. Palmate microtriches are abundant across the bothridium, but are not evident in regions posterior to the bothridial pits (asterisk). Fig. 3. Bothridial pit, enlargement of Fig. 2. Fig. 4. Palmate microtriches on surface of bothridium. Fig. 5. Bothridial pit, caps of bifid microtriches.

fibrils arranged in longitudinal or transverse bands (Figs. 8, 9, 15). Internally, the lumen of the sheath is lined by a thin cellular layer (Figs. 9, 15). Nuclei of this lining are abundant near the anterior extremity of the sheaths (Figs. 9, 15), but not posteriorly. Consequently, the inner cell lining of the tentacular sheath is represented in sections from posterior regions of the pars vaginalis by an extremely thin cytoplasm with irregularly spaced apical lamellae extending into the lumen of the sheath. The rhynchodeal fluid is electron-lucent and contains fine granular particles (Figs. 14, 15).

The tentacles are composed of a complex arrangement of cells and fibrils. The fibrils of the tentacular wall appear to be entirely intracellular (Figs.
16-19) and are arranged in discrete blocks of parallel fibrils (Figs. 19, 20). The external covering of the tentacles consists of a tri-laminar membrane underlain by a dense peripheral cytoplasm that is highly folded (Fig. 19). The membrane is lined externally by a moderately electron-opaque glycocalyx (Fig. 19). Cytoplasmic organelles, such as mitochondria, microtubules and vesicles occur between adjacent fibre blocks and between the blocks and external membrane (Fig. 19).

The internal surface of the tentacle wall consists of a complex assemblage of cells (Figs. 14, 16-18). Elongate membrane profiles are observed in the cytoplasm and give the impression that the tentacular wall is cellular 


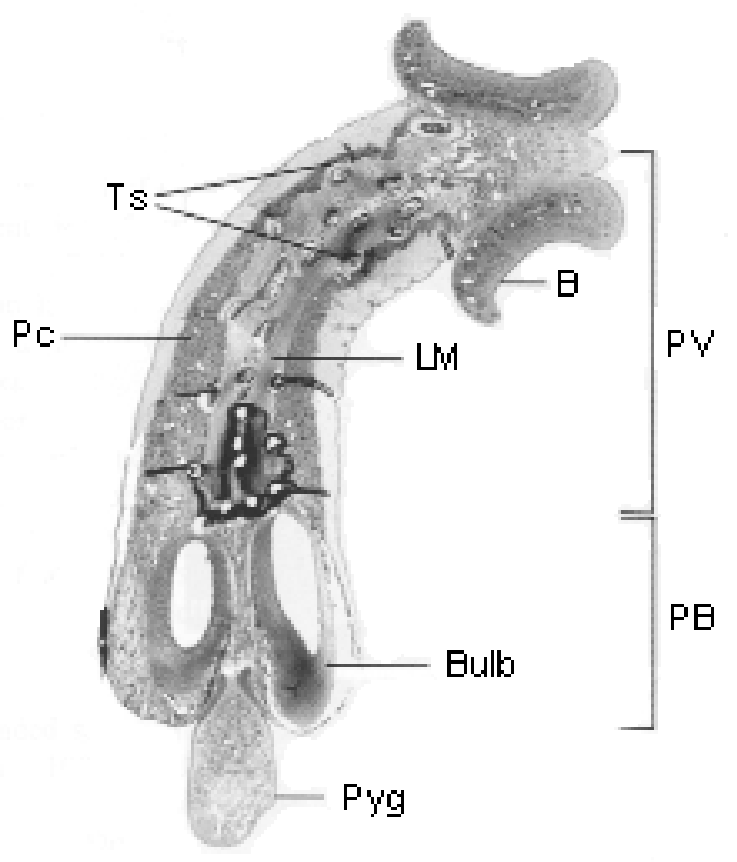

Fig. 6. Otobothrium mugilis, light microscopy, photomontage. The scolex is craspedote and bordered posteriorly by the pygidium (Pyg). Two bothridia (B) are evident. Tentacle sheaths (TS) pass anteriorly from bulbs, and follow a sinuous course to the apex of the scolex. Bands of smooth longitudinal muscle (LM) lie in close association with the tentacle sheaths. The parenchyma immediately surrounding the sheaths is rich in cells (PC). Abbreviations: $\mathrm{PV}$ - pars vaginalis; $\mathrm{PB}$ - pars bulbosa.

rather than syncytial and possibly consisting of more than one cell type. Numerous cytoplasmic structures including myofibrils, Golgi bodies, endoplasmic reticulum, glycogen granules, electron-opaque vesicles and nuclei are evident in this region (Figs. 14, 16-18).

Tentacular hooks are solid and are embedded in the fibre bundles of the tentacular wall (Fig. 17). The hooks are lined externally by a membrane (Fig. 19) that is continuous with the apical membrane of the tentacular wall. A thin, homogenous layer, consisting of an electron-lucent material lies beneath the membrane (Fig. $20)$. Most of the underlying body of the hook has a mottled appearance, arising from abundant longitudinal canaliculi with electron-opaque walls (Figs. 14, 17, 20).

A dense medulla, containing an electron opaque material, is present at the centre of the hooks (Fig. 17). This pattern of hook morphology was present in all samples regardless of fixation regime.

\section{DISCUSSION}

This ultrastructural study of the scolex of Otobothrium mugilis has shown that the bothridial pits are heavily muscularised invaginations of the bothridial tegument, and that they are lined with a peculiar form of microthrix not evident elsewhere on the scolex. Pintner (1934) provided a detailed review of light microscopical studies of the bothridial pits of trypanorhynchs. He showed that in a number of species, the bothridial pits appear as depressions or evaginated domes lined by elongate hair-like structures. A variety of names have been proposed for the pits, including sensory fossettes, retractile organs and ciliated pits. Linton (1890) observed that in fixed specimens of Otobothrium, the pits could either be retracted or everted and when everted, appeared as a ciliated papilla. Linton (1890) thought that the pits were rudimentary sense organs.

Sensory receptors and other nervous structures were not observed in any section through the bothridial pits of $O$. mugilis and therefore a sensory function for the pits for this species may be precluded. The pits are underlain by thick layers of subtegumentary muscles and are provided with a retractor muscle that extends into deeper regions of the bothridium. The nature of the subtegumentary musculature, and the occurrence of expanded bifid microtriches on the surface of the pits suggests that the pits are simple accessory holdfast structures, capable of being everted and withdrawn to grasp the host mucosa. Because the microtriches are bifid, it is postulated that the tips become splayed as the lining of the pit is pressed against the mucosal surface of the host, thereby providing greater purchase against the mucosa.

Bothridial pits are prominent structures when observed by light microscopy and clearly, are of systematic value. Palm (1997) presented arguments to incorporate all trypanorhynchs with bothridial pits into a single taxon, the Otobothrioidea (sensu Palm 1997), whereas Campbell and Beveridge (1994) separated trypanorhynchs with pits into different superfamilies based on their tentacular armature. The question arises, should bothridial pits be given priority as phylogenetic and systematic characters, as Palm (1997) proposes? The cladistic analysis of morphological character states of the trypanorhynchs by Beveridge et al. (1999) does not support Palm's proposal. The final answer to this question, however, may only be reached by comparative ultrastructural analyses of the bothridial pits of other trypanorhynchs, particularly the species Paranybelinia otobothrioides Dollfus, 1966 and Pseudonybelinia odontacantha Dollfus, 1966, which have pits but unlike Otobothrium possess homeoacanthous armature.

The present study has shown that the bothridial pits of $O$. mugilis are little more than simple elaborations of the existing bothridial tegument and associated 


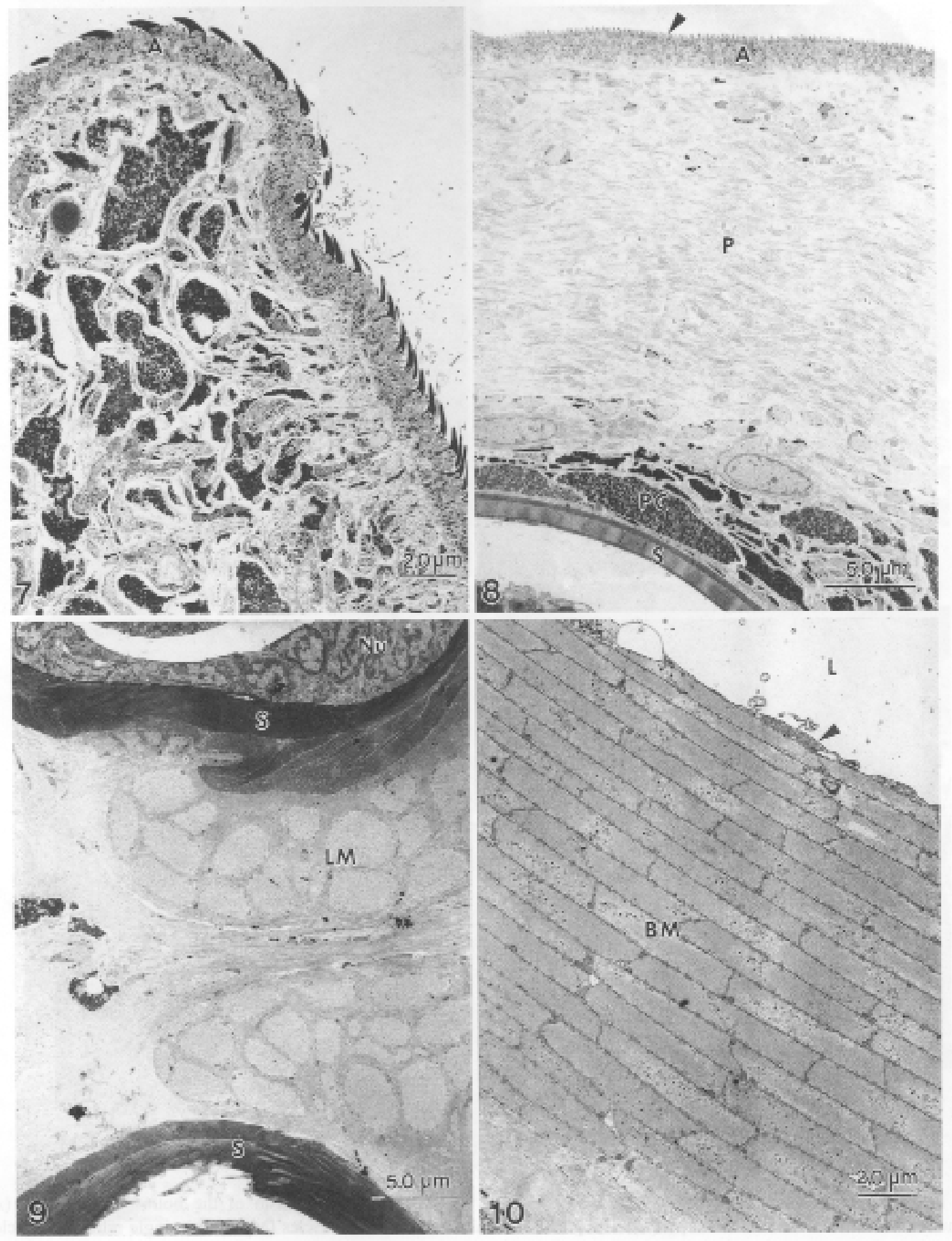

Figs. 7-10. Otobothrium mugilis, surfaces, TEM. Fig. 7. Bothridium, tegumental lining. The apical cytoplasm of the tegument (A) is covered with palmate and filamentous microtriches. The parenchyma is rich in cells containing abundant glycogen (asterisk). Fig. 8. Pars vaginalis, tegumental lining. The apical cytoplasm (A) is lined with filamentous microtriches (arrowhead). Note that the subtegumentary parenchyma (P) contains little cellular material. The parenchyma (PC) immediately surrounding the tentacle sheaths $(\mathrm{S})$, however, is richly cellular. Fig. 9. Tentacle sheaths $(\mathrm{S})$, from anterior region of the pars vaginalis. The inner lining of the sheath is thin and cellular, with abundant nuclear profiles $(\mathrm{Nu})$ evident. Longitudinal muscle fibres (LM) occur along the inner margin of each sheath. Fig. 10. Bulb musculature. Myofibrils (BM) are striated and arranged in discrete blocks. The lumen (L) of the bulb is lined with a thin, non-contractile region of cytoplasm (arrowhead). 


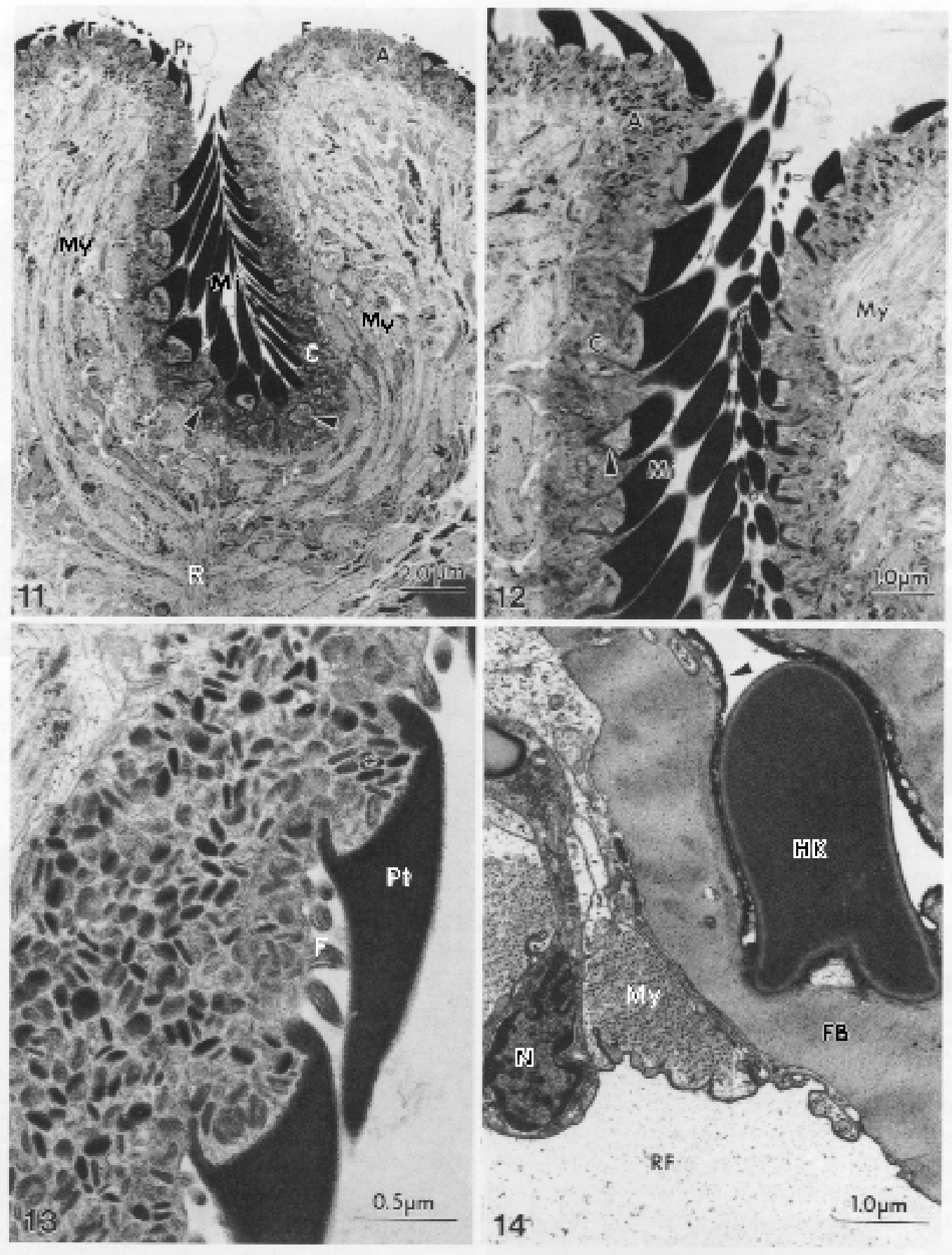

Figs. 11-14. Otobothrium mugilis, TEM. Fig. 11. Bothridial pit. The apical cytoplasm of the bothridial tegument (A) is continuous with that of the bothridial pit $(\mathrm{C})$. The pit is underlain with circular muscles (My) and a single retractor muscle (R) extends from the base of the pit. Note that the caps of the microtriches are embedded in the apical cytoplasm of the pits (arrowheads). The bifid microtriches of the pit (Mi) are larger than palmate (Pt) and filamentous (F) microtriches of the surrounding tegument. Fig. 12. Bothridial pit, showing apical cytoplasm (C), bifid microtriches (Mi) with caps embedded in apical cytoplasm (arrowhead), and circular musculature (My). Fewer tegumentary vesicles are apparent in the apical cytoplasm of the pit than in that of the surrounding tegument (A). Fig. 13. Apical cytoplasm of bothridium, distal surface, showing palmate microtriches (Pt), filamentous microtriches (F) and discoid bodies (asterisk). Fig. 14. Tentacular surface. The tentacular wall is cellular, and contains intracellular filaments arranged in blocks (FB). A hook (HK) is embedded in a block of fibres. Cellular material, including apparently discrete cells $(\mathrm{N})$ and myofilaments (My) are evident beneath the fibres of the wall. The rhynchodeal fluid (RF) is electron-lucent and contains a granular material. 

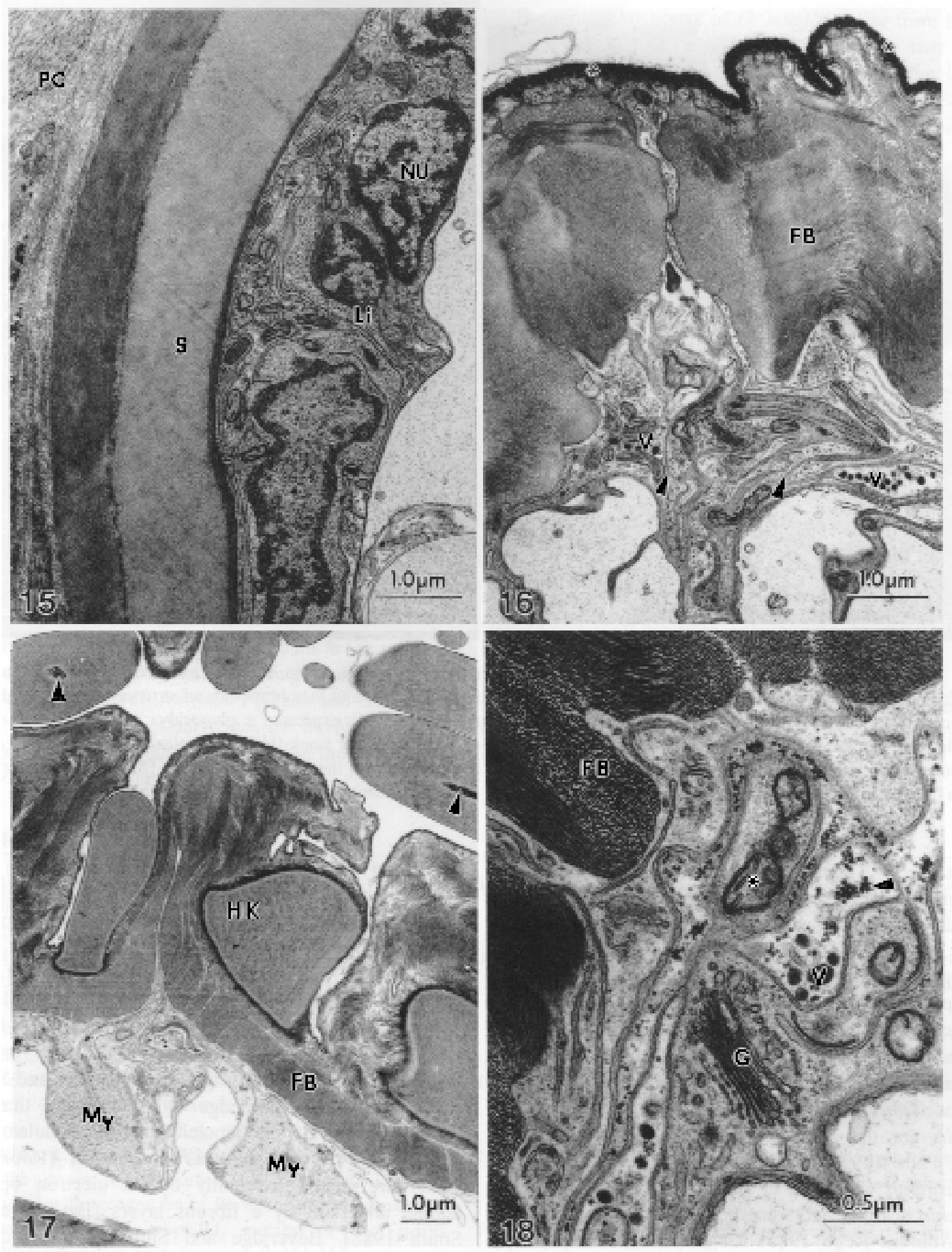

Figs. 15-18. Otobothrium mugilis, TEM. Fig. 15. Tentacular sheath. The sheath (S) is composed of discrete blocks of fibrils, that merges externally with the cell-rich parenchyma (PC). Internally, the lumen is bound by a cellular lining (Li), rich in nuclei $(\mathrm{Nu})$. Fig. 16. The wall is rich in fibrils (FB) that are intracellular and underlain by a cellular material with abundant membranes (arrowheads) and cytoplasmic components including electron-opaque vesicles (V). The apical membrane (asterisks) is a complex and electron-opaque. Fig. 17. Tentacular wall. Myofilaments (My) are observed in the cytoplasm beneath the block of fibrils (FB). Hooks are embedded in fibrils and are characterised by abundant canaliculi and an electron opaque medulla (arrowheads). Fig. 18. Basal cytoplasm of tentacular wall. The cytoplasm is rich in organelles including mitochondria (asterisk), Golgi bodies $(\mathrm{G})$, electron-opaque vesicles (V), and glycogen granules (arrowhead). FB - blocks of fibrils. 

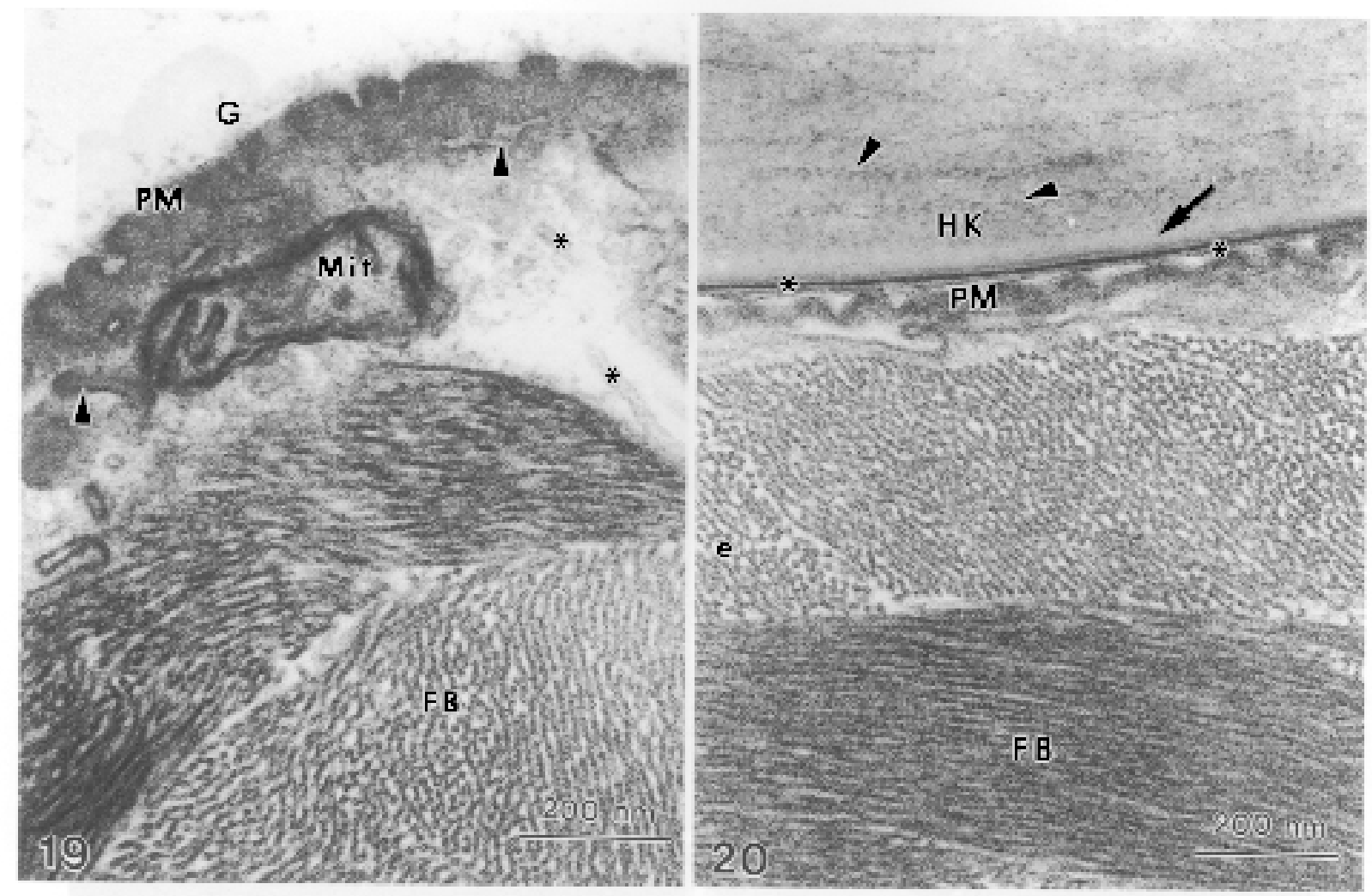

Figs. 19-20. Otobothrium mugilis, TEM. Fig. 19. Apical surface of tentacle. The fibrils appear to be intracellular and cytoplasmic structures, including mitochondria (Mit), microtubules (asterisks) and membrane-bound structures (arrowheads), lie between the blocks (FB) and apical membrane. The apical membrane (PM) expresses a glycocalyx (G) externally, and is underlain by a dense peripheral cytoplasm. Fig. 20. Juxtaposition of a tentacular hook (HK) and apical membrane (PM) of the tentacular wall. The membrane covering the hook (asterisk) is continuous with the apical membrane. The sub-membrane layer (arrow) is electron-lucent and is underlain by a material through which abundant canaliculi (arrowheads) pass.

musculature. The pits differ from the surrounding regions only in the nature of the microtriches and in the abundance and disposition of subtegumentary musculature. It is argued, therefore, that the microtriches and subtegumentary muscles of bothridial pits are likely to be key characters for further analyses of the interrelationships of trypanorhynchs.

The bifid microtriches covering the surface of the bothridial pits were not observed in other regions of the scolex. These microtriches are neither unique to $O$. mugilis nor the genus Otobothrium (see Palm et al. 1993, Palm 1995), having been described in Floriceps minacanthus Campbell et Beveridge, 1987, Callitetrarhynchus species, and some poecilacanths (see Carvajal and Arandas Rego 1985, Richmond and Caira 1991, Palm 1995), in which they occur along the transitional zone between proximal and distal bothridial surfaces, a position similar to that occupied by the bothridial pits of $O$. mugilis. Interestingly, the cladistic analysis of trypanorhynch cestodes (Beveridge et al. 1999), which was based on morphological characters but not including microthrix structure, showed that Floriceps and Callitetrarhynchus on the one hand, and Otobothrium on the other, belong to sister lineages (clades 6 and 7 of Beveridge et al., 1999) that approximate the Poecilacanthoidea (sensu Campbell and Beveridge 1994) and Otobothrioidea (sensu Campbell and Beveridge 1994).

Dollfus (1942) stated that the wall of the trypanorhynch tentacle consisted of a non-nucleated cuticle in which hooks were inserted, underlain by fibres and a cellular layer. Ultrastructural studies on the tentacles of other trypanorhynchs (Beveridge and Smith 1988, Jones and Beveridge 1998) suggests that the external lining of the tentacles is extracellular. The tentacles of Trimacracanthus aetobatidis (Robinson, 1959) are bound externally by an electron opaque lamina underlain by a fibrous layers (Beveridge and Smith 1988). Beveridge and Smith (1988) did not describe a cellular layer with nuclei, but they comment on the presence of vesicles and structures resembling myofilaments lying among the tentacular fibres. The tentacles of Nybelinia queenslandensis Jones et Beveridge, 1998 are complex, possessing a dense external lamina and underlain by many layers of fibrils (Jones and Beveridge 1998). A nucleated cellular layer supports the tentacular wall (Jones and Beveridge 1998), but appears to be separated from the wall by 
plasma membrane. The tentacles of Otobothrium mugilis are peculiar in that cytoplasmic constituents, such as mitochondria, are observed externally to the tentacular fibres, suggesting that the fibres are entirely intracellular and that the hooks originate intracellularly. Although the tentacles appear to be intracellular, the link between the sheath wall and lining cells is less clear. Externally, the sheath wall appears to merge with the parenchyma suggesting that its fibres are extracellular. Internally, the fibrils of the sheath wall are closely apposed to the cellular lining.

While it is apparent that the tentacles of $O$. mugilis are cellular, the nature of their cells is impossible to determine at this stage. Myofibrils are present in cells of the tentacle walls, indicating the presence of muscle. The tentacles of $T$. aetobatidis similarly appear to have muscle elements incorporated within the tentacle wall (Beveridge and Smith 1988). Since myocytons are suggested to play fibroblast-like role in cestodes (Conn 1993), it may be postulated that the tentacle walls are derived from parenchymal myocytons. This suggestion is strengthened by observations on the sheath walls which appear in Nybelinia and Otobothrium, at least, to merge with the extracellular matrices of the surrounding parenchyma. Myofibrils were not evident in the tentacle walls of Nybelinia, however, suggesting the involvement of other tissues in wall formation (Jones and Beveridge 1998). Studies on the early scolex development of trypanorhynchs are needed to determine the nature and origins of these structures.
The tentacular hooks of $O$. mugilis differ from those of $T$. aetobatidis and $N$. queenslandensis in that they possess internal canaliculi whereas those of the latter two species lack these structures (Beveridge and Smith 1988, Jones and Beveridge 1998). In N. queenslandensis, the blades of the hooks are slightly less electron-opaque than the basal regions, but nevertheless retain essentially the same structure in section. The strikingly different appearance of the hooks of Otobothrium suggests different biosynthetic pathways for the formation of hooks of different taxa and that comparative ultrastructural studies of the rhyncheal system may also be valuable in elucidating phylogeny of the Trypanorhyncha.

The bulbs musculature of $O$. mugilis is striated. Striated muscle is not common among platyhelminth worms, but has been described from taxa of all major classes of neodermatan platyhelminths. Thus, striated muscles are known from the cercarial tails of some digeneans, the tentacular bulbs of trypanorhynch cestodes, and the haptoral clamps of some monogeneans (Nuttman 1974, Ward et al. 1986). The striated muscle of $O$. mugilis bears close resemblance to that of Grillotia erinaceus van Beneden, 1858, which was described in detail by Ward et al. (1986).

Acknowledgement. Dr. I. Beveridge is thanked for his tuition on trypanorhynch systematics, for identifying specimens of $O$. mugilis and for constructive criticism of the manuscript.

\section{REFERENCES}

BEVERIDGE I., CAMPBELL R.A., PALM H.W. 1999: Preliminary cladistic analysis of genera of the cestode order Trypanorhyncha Diesing, 1863. Syst. Parasitol. 42: 29-49.

BEVERIDGE I., SMITH K. 1988: Ultrastructure of the rhyncheal system of Trimacracanthus aetobatidis (Cestoda: Trypanorhyncha). Int. J. Parasitol. 18: 623-632.

CAMPBELL R., BEVERIDGE I. 1994: Order Trypanorhyncha Diesing, 1863. In L. Khalil, A. Jones and R. Bray (Eds.), Key to the Cestodes of Vertebrates. CAB International, Wallingford, pp. 50-148.

CARVAJAL J., ARANDAS REGO A. 1985: Critical studies of the genus Callitetrarhynchus (Cestoda: Trypanorhyncha) with recognition of Rhynchobothrium speciosum Linton, 1897 as a valid species of the genus Callitetrarhynchus. Syst. Parasitol. 7: 161-167.

CONN D.B. 1993: The biology of flatworms (Platyhelminthes): parenchyma cells and extracellular matrices. Trans. Am. Microsc. Soc. 112: 241-261.

DOLLFUS R.-P. 1942: Etudes critiques sur les Tétrarhynques du Muséum de Paris. Arch. Mus. Natl. Hist. Nat., Paris, 6ème série, 19: 1-466.

HILDRETH M.B., LUMSDEN R.D. 1987: Microanatomy of the Otobothrium insigne plerocercus (Cestoda: Trypanorhyncha). J. Parasitol. 73: 400-410.
HISCOCK I.D. 1954: A new species of Otobothrium (Cestoda, Trypanorhyncha) from Australian fish. Parasitology 44: 65-70.

JONES M.K., BEVERIDGE I. 1998: Nybelinia queenslandensis sp. n. (Cestoda: Trypanorhyncha) from the shark Carcharhinus melanopterus from Australia, with observations on the fine structure of the scolex. Folia Parasitol. 45: 295-311.

LINTON E. 1890: Notes on Entozoa from marine fishes of New England. Part 2. Annu. Rep. Comm. Fish Fish. for 1887, Washington, pp. 849-853.

NUTTMAN C.J. 1974: The fine structure and organization of the tail musculature of the cercaria of Schistosoma mansoni. Parasitology. 68: 147-154.

PALM H. 1995: Untersuchungen zur Systematik von Rüsselbandwürmen (Cestoda: Trypanorhyncha) aus atlantischen Fischen. Ber. Inst. Meereskd. Kiel 275, 238 pp.

PALM H. 1997: An alternative classification of trypanorhynch cestodes considering the tentacular armature as being of limited importance. Syst. Parasitol. 37: 81-92.

PALM H., MÖLLER H., PETERSEN F. 1993: Otobothrium penetrans (Cestoda; Trypanorhyncha) in the flesh of belonid fish from Philippine waters. Int. J. Parasitol. 23: 749-755. 
PINTNER T. 1934: Bruchstücke zur Kenntnis der Rüsselbandwürmer. Zool. Jahrb., Abt. Anat. Ontog. Tiere 58: 120.

RICHMOND C., CAIRA J.N. 1991: Morphological investigations into Floriceps minacanthus (Trypanorhyncha: Lacistorhynchidae) with analysis of the systematic utility of scolex microtriches. Syst. Parasitol. 19: 25-32.

SHIELDS J.D. 1985: Surface morphology and description of Otobothrium kurisi new species (Cestoda: Trypano- rhyncha) from a hammerhead shark, Sphyrna lewini. Int. J. Parasitol. 15: 635-643.

WARD S.M., McKERR G., ALLEN J.M. 1986: Structure and ultrastructure of muscle systems within Grillotia erinaceus metacestodes (Cestoda: Trypanorhyncha). Parasitology 93: 587-597.

WARDLE R.A., McLEOD J.A. 1952: The Zoology of Tapeworms. The University of Minnesota Press, Minneapolis, $780 \mathrm{pp}$.

Accepted 15 September 1999

\section{3-5 May 2000}

\section{Course:}

\section{Evolution of Parasites and of Host-Parasite Relationships}

(Évolution des parasites et des relations hôtes-parasites)

Paris, France

Contact:

Dr. Marie-Claude Durette-Desset or Prof. Jean-Lou Justine

Laboratoire de Biologie Parasitaire, Helminthologie, Protistologie

Muséum National d'Histoire Naturelle, 61 rue Buffon,

75231 Paris cedex 05, France

Phone: + 33140793503

Fax: + 33140793499

e-mail: mcdd@mnhn.fr or justine@mnhn.fr

Programme: http://www.mnhn.fr/mnhn/bpph/ 